\title{
MOTIVATION AND SATISFACTION IN CONTEXT OF JOB TRAINING IN TOURIST ORGANIZATIONS
}

\author{
Rui Amaral ${ }^{1}$, Fátima Jorge ${ }^{1}$, Susana Rocha ${ }^{1}$, Margarida Saraiva ${ }^{2}$ \\ ${ }^{1}$ Universidade de Évora (PORTUGAL) \\ ${ }^{2}$ Universidade de Évora and BRU-UNIDE/ISCTE-IUL (PORTUGAL)
}

\begin{abstract}
This research aims to determine the dimensions of motivation and satisfaction, acquired, through the perception in context of job training, by future technicians (students) in the hospitality and tourism industry, particularly by technical courses in the hotel and restaurant sector. The methodology comprises three distinct stages. First were recovered instruments (questionnaires), already validated by other authors of motivation and satisfaction, which had the intention to replicate studies conducted in other scientific knowledge fields, such as tourism. Those instruments were recovered from the reviewed literature conducted about other themes. On second place the measuring instruments were submitted to a pre-test, or rather, were subject of a pioneer study, in order to verify other assumptions such as semantic errors or see if there was the possibility of some prepared questions to be consider invalidated by poor formulation or interpretation. Finally, were applied in three educational institutions who agreed to cooperate on the research, with the reservation that the interviewed needed a mandatory pre-requirement that consisted in conducting a minimum training in work context. Then, proceed the statistical analysis to support all the empirical part. The results show that, in general, motivation and satisfaction were present during the period of training in work context. To some people it meant a very important period of personal and professional life, concerning the interactions, emotions and involvement with touristic organizations but also the personal and social relationships.
\end{abstract}

Keywords: Motivation, satisfaction, training, tourist organizations.

\section{INTRODUCTION}

$\mathrm{HR}$ are confronted thus the "need to answer requests, increasingly complex and specific market niches characterized by competitiveness and increasing selectivity" ([3], p. 195). The numerous and varied reasons, it is not surprising that the reflections on human capital on the list of the main concerns of the leaders and managers of the hospitality industry. In fact the work of the "peace industry" is developed and has features contrary to other economies, due to seasonality, schedules and frequent turnover of Human Resources.

Perceive the motivation and satisfaction of these HR is especially important, since in contemporary society in which we live, the hospitality is guided by frequent industry and permanent acquisition of $\mathrm{HR}$, with levels of motivation and satisfaction increased over the rapid wear of the work but also the search for valid elements having special training, which makes the difference organizational success. In fact, these symmetries, employers, "are necessarily the valuation of training and qualification of human resources affects economic activity of tourism, as a key factor for sustainable development and to improve the competitiveness of the same" ([12], p. 39).

Among these attitudes, the perception of future young employees looking possibly first job prove to be important as the respective concepts are interconnected with the wishes of the tourist organizations. Thus this article reflects the relevance of the theme from the perspective of students unlike most studies that are concerned with studying the motivations and satisfaction of employees in service. We believe that future study perceptions of reviewers may be a gain to the extent that a better understanding of the role of future technical, in relation to the motivation and satisfaction may represent an increase in value and consequently increase productivity. The article consists of four points: the first reflects the main theoretical and conceptual elements. The methods of investigation are presented in the second section, while the third item are exposed and discuss the results. Finally, we present the findings, the study limitations and avenues for future work. 